\title{
Fault Simulation and Diagnosis for Heater Exchanger Base on BP Neural Network and Performance Parameters Deviation
}

\author{
Shidan $\mathrm{Chi}^{1}$, Xudong $\mathrm{Gao}^{2}$, Yan Liang ${ }^{3}$, Xundong $\mathrm{Hu}^{4}$, Tao $\mathrm{Luan}^{5}$, and Yan $\mathrm{Gao}^{6}$ \\ ${ }^{1}$ School of Energy and Power Engineering, Shandong University, Jinan 250061, China \\ ${ }^{2}$ Power Plant Performance Index Research Center, Shandong Electric Power Engineering Consulting \\ Institute Corp.,LTD, Jinan 250061, China \\ ${ }^{3}$ Department of Project Manager, Shandong Electric Power Engineering Consulting Institute Corp.,LTD, \\ Jinan 250061, China \\ ${ }^{4}$ Department of Project Manager, Shandong Electric Power Engineering Consulting Institute Corp.,LTD, \\ Jinan 250061, China \\ ${ }^{5}$ Engineering Laboratory of Power Plant Thermal System Energy Saving of Shandong Province, Shandong \\ University, Jinan 250061, China \\ ${ }^{6}$ Department of Thermal Engineering, Shandong Jianzhu University, Jinan 250101, China
}

Keywords: Heater, Fault Diagnosis, Neural Network, Target value, Performance Parameter.

\begin{abstract}
There are problem of complex characteristic variables and low diagnostic efficiency in the performance monitoring and fault diagnosis of heaters in thermal systems. This paper prevents a composite diagnostic model based on the BP neural network model. This model can simulate the heat transfer process of heater and performance monitoring and fault diagnosis of heaters. At the same time, the concept of heater target value and benchmarking is proposed. Nine optimal characteristic variables are selected from the 18 parameters that affect real heat transfer process of the heater as input parameter, three variables are output parameter. The results show that: This model can realize the calculation and benchmarking of output parameter's target value in off-design operating condition. The heater failure diagnosis under off-design operating conditions can be realized by benchmarking result. This model has higher credibility and reliability.
\end{abstract}

\section{Introduction}

The power plant heat exchanger is an important equipment in the power plant regenerative system. The operating environment of heater, especially the high pressure heat exchanger operating environment is relatively bad, and the parameters such as feed water pressure and steam extraction temperature are higher. So it is prone to failure during operation [1]. When problems occur during operation, the economic decline caused by the removal of the high pressure heat exchanger is more obvious. According to the information provided by the steam turbine factory, taking the supercritical 660MW unit as an example, the heat consumption increases about 300kJ / kwh caused by the removal of the high pressure heat exchanger. Therefore, the operation performance of high-pressure equipment has an important impact on the unit economics. It is of great significance to do a good diagnosis of the heat exchanger faults, find out the problems in the equipment operation in time, and give out a solution as soon as possible.

Many studies have done a lot of work on heat exchanger fault diagnosis [2 10]. From the current research, it is mainly divided into two methods based on mathematical models and knowledge-based research. It is difficult to establish an accurate and relatively simple mathematical model to describe the heater's heat exchange process because of the complexity and non-line characteristic. Therefore, the application of research methods based on mathematical models is limited. In recent years, knowledge-based diagnosis method has been widely concerned. Especially, the study combining with neural network algorithm is more common which uses empirical knowledge to determine equipment fault mode through fault classification, not relying on 
mathematical model.

\begin{tabular}{cccc}
\hline \hline$\theta$ & Symbols & LE & Low-temperature economizer \\
\hline$t_{p}$ & $\begin{array}{c}\text { heater upper terminal temperature } \\
\text { difference }\left({ }^{\circ} \mathrm{C}\right)\end{array}$ & $\begin{array}{c}G_{d r} \\
\text { Heater steam side } \\
\text { temperature }\left({ }^{\circ} \mathrm{C}\right)\end{array}$ & $\begin{array}{c}\text { upperheater drain water flow } \\
\text { rate }(\mathrm{kg} / \mathrm{h})\end{array}$ \\
$t_{w}$ & feed water inlet temperature $\left({ }^{\circ} \mathrm{C}\right)$ & $h_{p}$ & $\begin{array}{c}\text { heater extraction enthalpy }(\mathrm{kJ} / \mathrm{kg}) \\
\text { saturation temperature enthalpy } \\
\text { corresponding to extraction pressure } \\
(\mathrm{kJ} / \mathrm{kg})\end{array}$ \\
$G_{w}$ & feed water flow rate $(\mathrm{kg} / \mathrm{h})$ & $h_{o d}$ & $\begin{array}{c}\text { drain water enthalpy }(\mathrm{kJ} / \mathrm{kg}) \\
\text { Feed water specific heat capacity of } \\
\text { feed water at constant } \\
\text { pressure }\left(\mathrm{kJ} /\left(\mathrm{kg} \cdot{ }^{\circ} \mathrm{C}\right)\right)\end{array}$ \\
\hline \hline
\end{tabular}

\section{Heat exchanger target value calculation model}

\subsection{Heat exchanger target value calculation principle}

The heat exchanger heating exchange process follows the material balance and heat balance. When operating under the design conditions, the outlet water parameters and hydrophobic parameters of the heat exchanger can be got through the design parameter calculated of steam extraction, feed water, flow rates, and terminal temperature differences.

However, if the unit operates under off-design conditions with the load changing, the steam extraction parameters and the feed water flowrate will change. When these parameters change at the same time, the terminal temperature difference of the heater will also change. In the traditional calculation modeling method, analyzing the specific parameter change is related to the internal structure of the heat exchanger and a heat exchanger heating transfer model.

The internal heat exchange calculation of the heater is adjusted according to parameters changes. The Prandtl number, Reynolds number, etc. need to be checked according to the flow, and calculated based on the empirical formula with the heater's parameter changes. This process is quite complicated and the accuracy of the calculation result is difficult to guarantee because of empirical formulas using.

Some studies have carried out numerical simulations of the heater's under off-design conditions [11]. Those studies build databases by numerical simulation and compare the operation value with the target valueof terminal temperature difference. A terminal temperature difference calculation equation under off-design conditions is built for non-steam cooling section heat exchanger and non-hydrophobic cooling section heat exchanger.

$$
\theta=\theta_{0} \cdot\left(\frac{t_{p}-t_{w}}{t_{p 0}-t_{w 0}}\right)^{1.26} \cdot\left(\frac{G_{w}}{G_{w 0}}\right)^{2.02}
$$

Based on Eq.(1), related research has extended [12] and formed the upper terminal temperature difference equation under off-design condition for the three-stage heat exchanger.

$$
\begin{array}{r}
\theta=\left[\theta_{0}+\frac{G_{s 0}\left(h_{s 0}-h_{p 0}\right)}{G_{w 0} c_{p 0}}\right] \cdot\left(\frac{t_{p}-\left(t_{w}+\frac{G_{s}+G_{d r}}{G_{w} c_{p}}\left(h_{p}-h_{o d}\right)\right)}{t_{p 0}-\left(t_{w 0}+\frac{G_{s 0}+G_{d r 0}}{G_{w 0} c_{p 0}}\left(h_{p 0}-h_{o d 0}\right)\right.}\right)^{1.26} \\
\cdot\left(\frac{G_{w}}{G_{w 0}}\right)^{2.02}-\frac{G_{s}}{G_{w} c_{p}}\left(h_{s}-h_{p}\right)
\end{array}
$$

\subsection{High pressure heater failure sample data base and symptom signal}

Common faults of power plant heater are as follows: (1) the water level is too high or too low; (2) the reducing of heat exchange efficiency; (3) the failure offeed water system; (4) water pipe leakage, 
etc. Especially, according to the specific reasons, these faults can be divided into 9 type faultsin detail (see Table 1).

Table.1Fault type and symptom table

\begin{tabular}{|c|c|c|}
\hline Item & Fault type & Fault symptom \\
\hline 1 & Air accumulation & $\begin{array}{l}\text { Low feed water temperature inoutlet \& low temperature of drain } \\
\text { water }\end{array}$ \\
\hline 2 & Dirty piping & $\begin{array}{c}\text { Low feed water temperature in outlet r\& high temperature of drain } \\
\text { water }\end{array}$ \\
\hline 3 & Heater piping blocked & $\begin{array}{l}\text { Low feed water temperature in outlet\& high temperature of drain } \\
\text { water\& high pressure of heater's water side }\end{array}$ \\
\hline 4 & Bypass failure & Bypass valve open \&highfeed water temperaturein outlet \\
\hline 5 & $\begin{array}{l}\text { Water charm of heater } \\
\text { short circuit }\end{array}$ & $\begin{array}{l}\text { Low feed water temperature in outlet\& low pressure drop on water } \\
\text { side }\end{array}$ \\
\hline 6 & Tiny leakage & $\begin{array}{l}\text { Low feed water temperature in outlet\& low pressure drop on water } \\
\text { side }\end{array}$ \\
\hline 7 & Piping damage & $\begin{array}{l}\text { Pressure rise on the shell side of heater \& obvious rise of water } \\
\text { level \& obvious decrease of pressure drop on water side }\end{array}$ \\
\hline
\end{tabular}

The table shows that the fault symptoms are closely related to the outlet feed water temperature, drain water temperature, water side pressure drop, water level and valve opening. Those parameters should be determined first in order to achieve fault diagnosis. However, some of the above symptoms can be directly obtained, such as the water level, whether the valve is faulty or not. Some symptoms such as low feed water temperature are difficult to judge. Because the heater is in off-design operating mode during unit actual operation, various conditions will cause the feed water temperature in heater outlet to be low. Therefore, the target values of feed water and drain temperature of the heater outlet can be calculated according to the calculation model as compared basis.

\subsection{BP neural network model of heater}

Based on the research on high pressure heater failure sample and symptom signal, nine parameters are selected as input parameters of BP neural network model: pressure, temperature and flow of heater water side inlet, pressure and temperature of heater steam side inlet, drain temperature of upper level, unit power generation on time and one minute ago, drain temperature of heater one minute ago. Three parameters are selected as output: feed water temperature, drain temperature and pressure drop at the outlet of the heater. The middle layer (i.e. the hidden layer) is the corresponding switch between input and output. The number of hidden layer nodeissix.

Enough training samples can guarantee the accuracy of calculation model. No.2 high pressure heater of one $300 \mathrm{MW}$ power plant is taken as a research object. 1000 data groups of different load are selected to train BP neural network model. In addition, 100 groups of data are randomly selected for verification. Using this model to predict the target value of 100 data groups, and comparing with the actual operation value, the curvesfromFig.1 to Fig. 3 are obtained.

Fig. 1 shows the comparison of target value and the actual operation value of the feed water temperature at heater outlet. It shows that this two are very close. The maximum difference is about $1.2{ }^{\circ} \mathrm{C}$, and the maximum prediction deviation is only $0.52 \%$. The prediction effect is good.

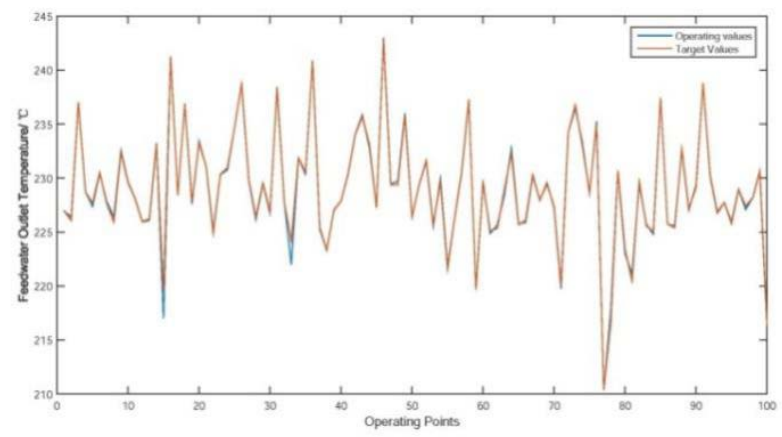

Fig.1Comparison of real-time value to target valueof outlet feed-water temperature 
Fig.2 shows the comparison between the target value and real-time value of the drain temperature at the steam side of the heater. It can be seen that the prediction effect is good. But the error ratevis larger than Fig. 1, the maximum error is about $2.6^{\circ} \mathrm{Cand}$ the maximum prediction error rate is $1.18 \%$. This prediction accuracy can also meets the engineering needs.

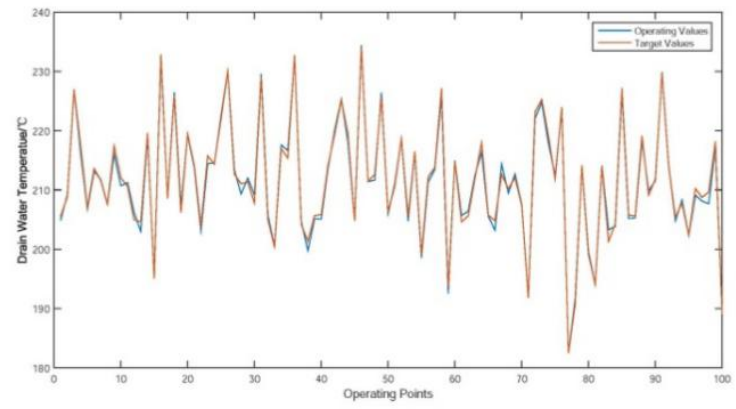

Fig.2Comparison of real-time value to target value of drain water temperature

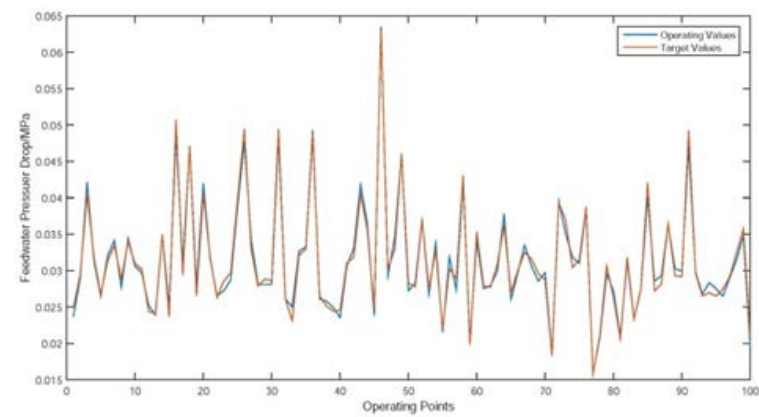

Fig.3 Comparison of real-time value to target value of feed water pressure drop

Fig. 3 shows the comparison curve of feed water pressure drop, with the maximum error of 0.0021mpa. The overall prediction effect is also good, which can well reflect the resistance of the equipment during operation.

In order to prevent the diagnostic results from being affected by the errors in the prediction process of the target value, we take the maximum error of the above results as the maximum allowable deviation range of the output parameters. If it exceeds this range, the heater is considered to be faulty.

In order to prevent the errors in the prediction of the target value from influencing the diagnosis result, the maximum errors of outlet feed water temperature, hydrophobic temperature and pressure drop are taken as the allowable range of the calibration result, the ranges are $\left(-1.5^{\circ} \mathrm{C}, 1.5^{\circ} \mathrm{C}\right)$, $\left(-3^{\circ} \mathrm{C}, 3^{\circ} \mathrm{C}\right),(-0.003 \mathrm{Mpa},-0.003 \mathrm{Mpa})$ respectively. If the calibration results exceed this range, the heater is considered to be faulty.

\section{Heater fault diagnosis based on target value analysis}

We select nine parameters real-time value from SIS system in the power plantas the model input. During diagnosis, the operation value can be obtained by SIS system of power plant in real time. The target value is calculated in real time according to 9 inputs (also from SIS system) with neural network model. The calculated target value is compared with the operation value by comparison. When the error between the two exceeds the above critical range, the diagnosis process is entered. The specific logic diagram of diagnosis process is shown in Fig.4. 


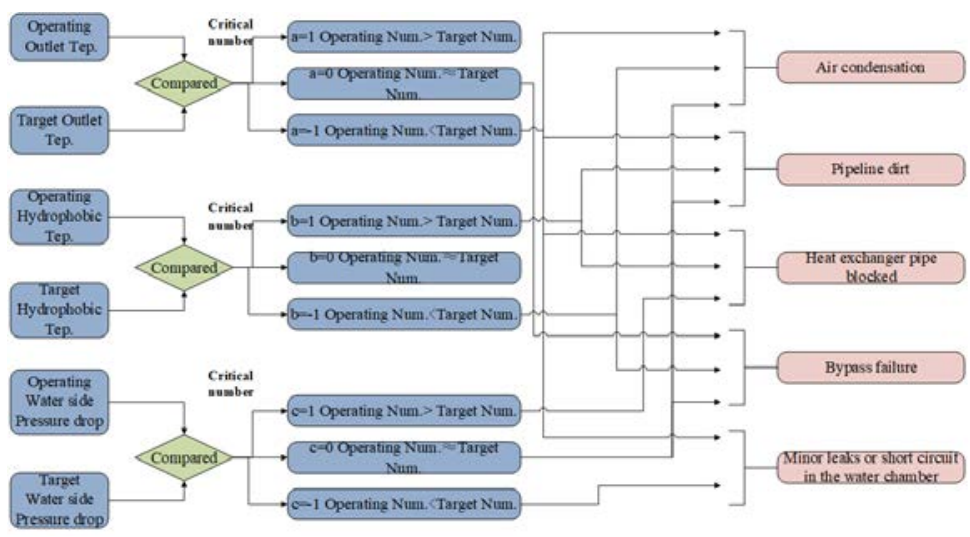

Fig.4 Fault diagnosis logic diagram of heat exchanger

The three parameters of heater out letare respectively judged by the above benchmarking which is shown in Fig.4. After a, b and c are obtained, accident reasoning is performed according to the combination of the three target values. When the three target values meet the corresponding conditions of several faults on the right, the current fault can be judged as such fault, and an alarm and operation guidance window will pop up.

After testing, when the actual operation indicators deviate, the heater diagnosis system can judge the fault according to the number and type of deviation indicatorsand pop up a window to give an alarm and guide the staff to eliminate the failure.

\section{Conclusion}

This study classifies common faults of heater, analyses the fault process, and obtains the corresponding fault symptoms when various faults occur, which lays the foundation for fault diagnosis. The traditional mechanism model has limitations in calculating variable operating conditions because that the off- design calculation of the heater is complicated and some flow data cannot direct measure on site.

Therefore, this paper proposes a neural network model of heater based on theoretical analysis. The results reveal the followings.

(1) The input and output parameters of BP neural networkheater model are determined. Inputs: pressure, temperature and flow of heater water side inlet, pressure and temperature of heater steam side inlet, drain temperature at the upper level, power generation, drain temperature of the heater one minute ago, and power generation one minute ago. Outputs: feed water temperature, drain temperature and pressure drop of heater outlet.

(2) The maximum calculation errors of the model's outlet feed water temperature, hydrophobic temperature, and feed water outlet pressure drop are $1.2{ }^{\circ} \mathrm{C}, 2.6^{\circ} \mathrm{C}$, and $0.0021 \mathrm{Mpa}$, respectively. The benchmarking range of failure model are $\left(-1.5^{\circ} \mathrm{C}, 1.5^{\circ} \mathrm{C}\right),\left(-3^{\circ} \mathrm{C}, 3^{\circ} \mathrm{C}\right),(-0.003 \mathrm{Mpa},-0.003 \mathrm{Mpa})$ respectively.

(3) The BP neural network model can calculate the three target values of the heater and it is benchmark which with the real-time operating data, taking into account certain errors, and combining the fault diagnosis logic diagram to realize the fault diagnosis of the heater.

\section{Acknowledgments}

This research was supported by Scientific Research Project of State Power Investment Group (Research on Performance Indexes Diagnosis Technology of Power Plants Energy-saving and Efficiency-enhancing, Project number: SNPTC-C04-2018-0006).

\section{References}

[1] Wang Qi-long. Study and development of fault diagnosis system for steam turbine unit in power 
plant [D]. Nanjing. Southeast University, 2000.(in Chinese).

[2] Ma Liang-yu, GAO Jian-qiang, WANG Bing-shu, et al. Fuzzy pattern recognition used for fault diagnosis of the high-pressure feed-water heater system of a 300MW thermal power generating unit[J]. Electric Power, 2002,35 (6): 32-35. (in Chinese).

[3] Song Hong-ru, DING Chang-fu, FENG Yu-zhao, The use of RBF neural network to fault diagnosis in high-pressure heater. North East Electric Technology. 2008, (11), 15-18.(in Chinese).

[4] Zhang Xin-gang LI Yong, XU Zhi-gao, et al.Dynamic numerical simulation and fault characteristic extraction of high-pressure feed water heater[J], Turbine Technology. 2004, 46(2): 132-134.(in Chinese).

[5] Liang Na, DING Chang-fu, DING Zhen-yu. Fault diagnosis and simulation for high-pressure heaters based on probabilistic neural network[J]. Power Eqipement, 2010, (02):97-100. (in Chinese).

[6] Zhang Xiao, LI Lu-ping, CHEN La-min, et al. Experiment study of inner leakage in heat exchanger [J]. Journal of Engineering for Thermal Energy and Power, 2011, 26(01):63-66.(in Chinese).

[7] LuoGuibing, LI Chong-xiang. Fault diagnosis model for reheating system based on LM neural network [J]. Thermal Power Generation, 2004(10):15-18.(in Chinese).

[8] Ma Liang-yu, LIU Ting. Neural Network Based Internal Leakage Fault DiagnOsis for Low-Pressure Heater System under Multiple Load Points [J]. computer measurement \& control, 2016, 24(2) :57-60.(in Chinese). 